\title{
EL TECPAN DE TLATELOLCO
}

\section{Por Carlos Flores Marini}

Después de fundada la ciudad de Tenochtitlan los aztecas sufrieron una crisis interna por conflictos políticos, que trajo como consecuencia la separación de una parte del grupo, el cual emigró hacia un islote cercano, de nombre Tlatelolco, donde fundaron una pequeña aldea el año de 1338. Andando el tiempo y debido a que tanto Tlatelolco como Tenochtitlan pertenecían al señor de Azcapotzalco, al cual servían como mercenarios, los tlatelolcas le pidieron uno de sus hijos para que los gobernara, designando para este efecto a Quacuapitzáhuac.

A medida que el grupo se establecía firmemente en Tlatelolco, su población se dedicaba principalmente al comercio y a la agricultura y poco a poco adquiría fuerza económica y polftica. Al alcanzar su independencia han evolucionado de un grupo trival a una sociedad fuertemente estratificada con dos grupos sociales predominantes: los "macehuales" o proletarios y la nobleza o "pilli". Las conquistas militares y la gran expansión del comercio hacen que las ciudades gemelas de Tenochtitlan y Tlatelolco adquieran una gran importancia dentro de las culturas mesoamericanas.

En el siglo xv, en 1475, las dos ciudades se enfrentan en guerra, siendo Tlatelolco la vencida lo que trae como consecuencia que a partir de ese momento se forme la unidad política, económica y militar, conocida como la gran ciudad de México Tenochtitlan-Tlatelolco, en la que esta última es gobernada por un tlacatécatl tenochca.

Desde muy temprano se establece en Tlatelolco el tianguis o gran mercado de la ciudad, el cual tenia en el momento de la conquista un adoratorio central y una buena casa de audiencias donde se encontraban permanentemente de diez a doce jueces. El adoratorio central era muy pequeño para estos menesteres de tal manera que es probable que los jueces y el gobierno estuvieran en el lugar que actualmente ocupa el "tecpan". No es posible suponer que las autoridades civiles se encontraran asentadas en la parte comprendida en el recinto del gran templo mayor y tampoco en las instalaciones del mercado ya que las exploraciones arqueológicas registraron almacenes en este lugar y bodegas en la parte norte y sur del actual jardín de Tlatelolco, lógico es suponer que el asiento del antiguo palacio era el "tecpan" que significa precisa- 
mente: palacio, es por ello que los arqueólogos creen que el sitio no ha sufrido ningún cambio de lugar desde su fundación. 1

Después de la guerra con Tenochtitlan, el tecpan fue asiento de los gobernadores militares, hasta Cuauhtémoc que fue nombrado señor de Tlatelolco cuatro años antes de la conquista española; es significativo hacer notar que el tecpan quedaba frontero al calpulli de Atennantitetech, lugar donde estaba el hogar de Cuauhtémoc. Al rendirse Tenochtitlan y Tlatelolco a los españoles, empieza la repoblación de esta población, donde se acomodan los supervivientes de la ciudad de México, Tlatelolco por su especial carácter, queda fuera de la "traza" que se compone con los cuatro antiguos campan de Tenochtitlan, siendo desde entonces un barrio indígena de México con residencia del cacique; Cuauhtémoc el primero de ellos. Al establecerse el régimen colonial, Tlatelolco conserva ciertos privilegios dentro del virreinato español, por lo que se reconoce a su nobleza indígena derechos y prerrogativas, asi, Cuauhtémoc sigue siendo rey de México y señor de Tlatelolco y como tal manda pintar la llamada Ordenanza de Cuauhtémoc, en la que reclama derechos territoriales para Tlatelolco y jurisdicción de pesca.

De acuerdo con los datos históricos, el tecpan no solo era residencia oficial del cacique, sino sede del poder civil, ya que tenía lugares destinados para los recaudadores de rentas, funcionarios civiles y policiales (topiles) que mantenian el orden en su jurisdicción. Hay que hacer notar que de acuerdo con los privilegios que conserva Tlatelolco, esta población tenía autonomía en el ramo civil en el que dependía directamente de la Real Audiencia y del virrey, con total exclusión de otras autoridades incluyendo el Tribunal del Santo Oficio. También era sede de la justicia territorial en lo concerniente a delitos menores, de donde pasaban las causas criminales directamente a la audiencia de México.

En el orden religioso fueron los franciscanos los que administraron el templo dedicado a Santiago Apóstol, junto con las ermitas del barrio como: Santa Ana, el Calvario, San Antonio el pobre, etcétera, y el Imperial Colegio de la Santa Cruz, del que llega a ser rector Antonio Valeriano, indígena puro de Azcapotzalco. Al finalizar el siglo xvi, el imperial colegio deja de tener importancia como centro de estudios humanísticos superiores, para convertirse durante el siglo xvir en una modesta escuela de primeras letras para niños indígenas. Aunque ya para

1 Agradezco al arqueólogo Francisco González Rul todas las informaciones que se sirvió proporcionarme. 
fines de este siglo Tlatelolco ha perdido su importancia económica y política, el tecpan conserva el carácter de sede gubernamental hasta el primer tercio del siglo $\mathrm{xIx}$, cuando es definitivamente suprimido.

El año de 1850, el ayuntamiento de la ciudad decide tomar en arren. damiento el tecpan de Santiago por la cantidad de veinticinco pesos mensuales, para establecer en él un "Asilo Independiente para los Corregidos", separando así de la correccional a los jóvenes que principiaban en la delincuencia, dándosele el año de 1853, el nombre de: "Colegio Correccional de San Antonio." 2

Funcionó como tal hasta el año de 1909 en que se destinó a escuela, primero con el nombre de "Manuel Eduardo Gorostiza", después como "Escuela Industrial y Vocacional de la Beneficiencia Pública" y finalmente a partir del 15 de febrero de 1943, como escuela diurna y nocturna ES1-16 "Pedro Díaz", hasta el dia 12 de mayo de 1962 en que con motivo de las obras del conjunto urbano "Nonoalco-Tlatelolco" los alumnos son trasladados a unas aulas de emergencia con objeto de ejecutar las obras necesarias para convertir el tecpan en "recinto de homenaje a Cuauhtémoc".

Los datos más antiguos relativos a la construcción del edificio nos lo proporciona el llamado Códice del Tecpan de Santiago Tlatelolco (15751581), el cual contiene el programa arquitectónico de la reconstrucción y el costo y tiempo empleado en dicha obra así como una pintura donde se ve representado.

Por la importancia del Documento es necesario transcribir integramente las obras a ejecutar, ya que aunque fueron publicadas por el doctor Justino Fernández, es quizás el documento más antiguo de esta indole que poseemos. Las distintas obras consistían en:

Una gran casa de recepción, con 19 salones y 3 o 4 ventanas en las grandes salas. Esta casa estaría destinada a recibir a cualquier virrey o personaje ilustre. Deberia dar hacia el sur con 16 o 17 portales (tramos intercomunales) y en medio la fachada con 56 varas (de longitud). Otra casa de recepción (hospederia o mesón) hacia el norte, con 12 piezas, una grande, en el centro destinada al descanso de los señores que viniesen de lejos y en una esquina estaría la oficina de los escribanos (30/2 varas). Se marcan los linderos.

2 M. Rivera Cambas. México pintoresco, artistico y monumental, México 1882 , pp. 81-86. 
El tribunal, una gran audiencia y la cárcel una para hombres y otra para mujeres. Todo tendria 200 varas.

19 casas dentro de la casa (sic) con pisos superiores destinados para viviendas de los señores.

Una casa de descanso (excusados junto a la casa y 5 piezas). Huerta. Jardín. Baño con 5 piezas. Pilas de agua, una en el centro y caños para el agua potable.

En la segunda parte del manuscrito, informan los vecinos de la terminación de los trabajos que se les encargaron y del costo:

Los que se hicieron la casa de recepción dicen que costó cuatro mil pesos, que la empezaron el 7 de marzo y la terminaron el 11 de agosto del mismo año.

Los que construyeron la casa de los señores dicen que costó cuatro mil pesos y que la obra se concluyó el 20 de noviembre de 1576 .

Los que fabricaron la casa para el tribunal, la audiencia y la cárcel, dicen que costó cuatro mil doscientos pesos y 12, y que terminaron el 14 de febrero de 1577.

Los que levantaron las viviendas para los señores, dicen que costaron cuatro mil ochocientos pesos y que dieron fin al trabajo el 3 de julio de 1577.

Los que se encargaron de construir los pisos superiores, dicen que costaron cuatro mil pesos y que terminaron el 4 de enero de 1578.

Los que se hicieron Ia casa de descanso gastaron dos mil ochocientos pesos y concluyeron su trabajo en abril de 1579 .

Los que se ocuparon de plantar la huerta y el jardín dicen que todo costó cuatrocientos pesos y que dieron fin a su encargo el 3 de junio de 1578.

Se asienta, al final, una partida de diez mil pesos con fecha 30 de septiembre de 1579; una nota sobre la conclusión de la casa comunidad, el 5 de septiembre de 1580 , otra diciendo que la obra se comienza siendo virrey don Martín Enríquez y que se terminó el 24 de junio de 1581, habiéndose inaugurado el día del Santo Santiago y que ese día llega el virrey Lorenzo Suárez de Mendoza y la consagra el arzobispo de México, don Pedro Moya de Contreras. Los últimos párrafos se refieren a los seis mil pesos que dejó, en parte, Miahuatototzin (sic) varfan a la fecha de terminación de la casa de comunidad y asientan el 24 de julio de 1581 , y, tras de hacer constar una vez más que la construcción se hizo con lo que dejaron Cuauhtemotzin y Miahuatototzin firman este libro 
DOI: http://dx.doi.org/10.22201/iie.18703062e.1968.37.858

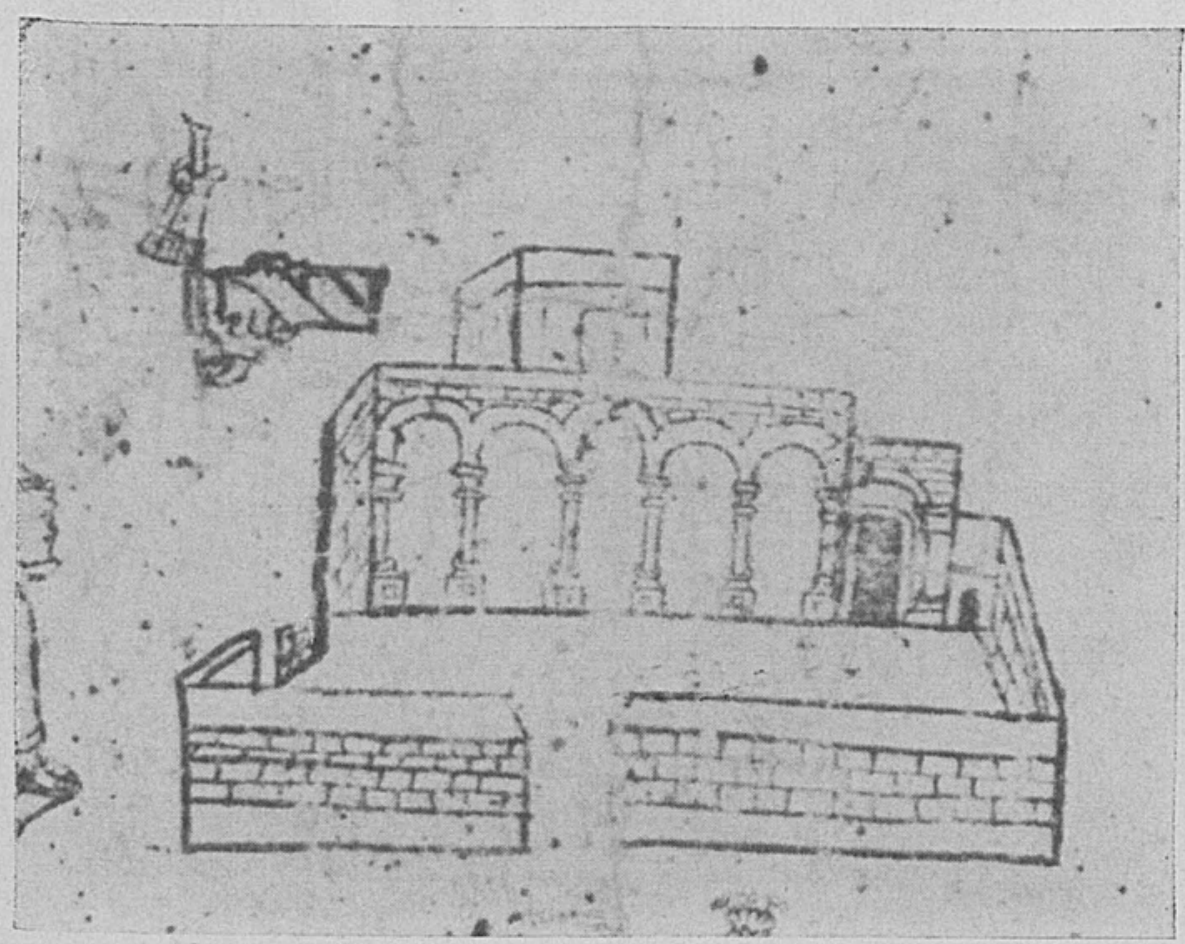

1. Representación del Tecpan en el Códice de Tlatelolco. Circa 1565 


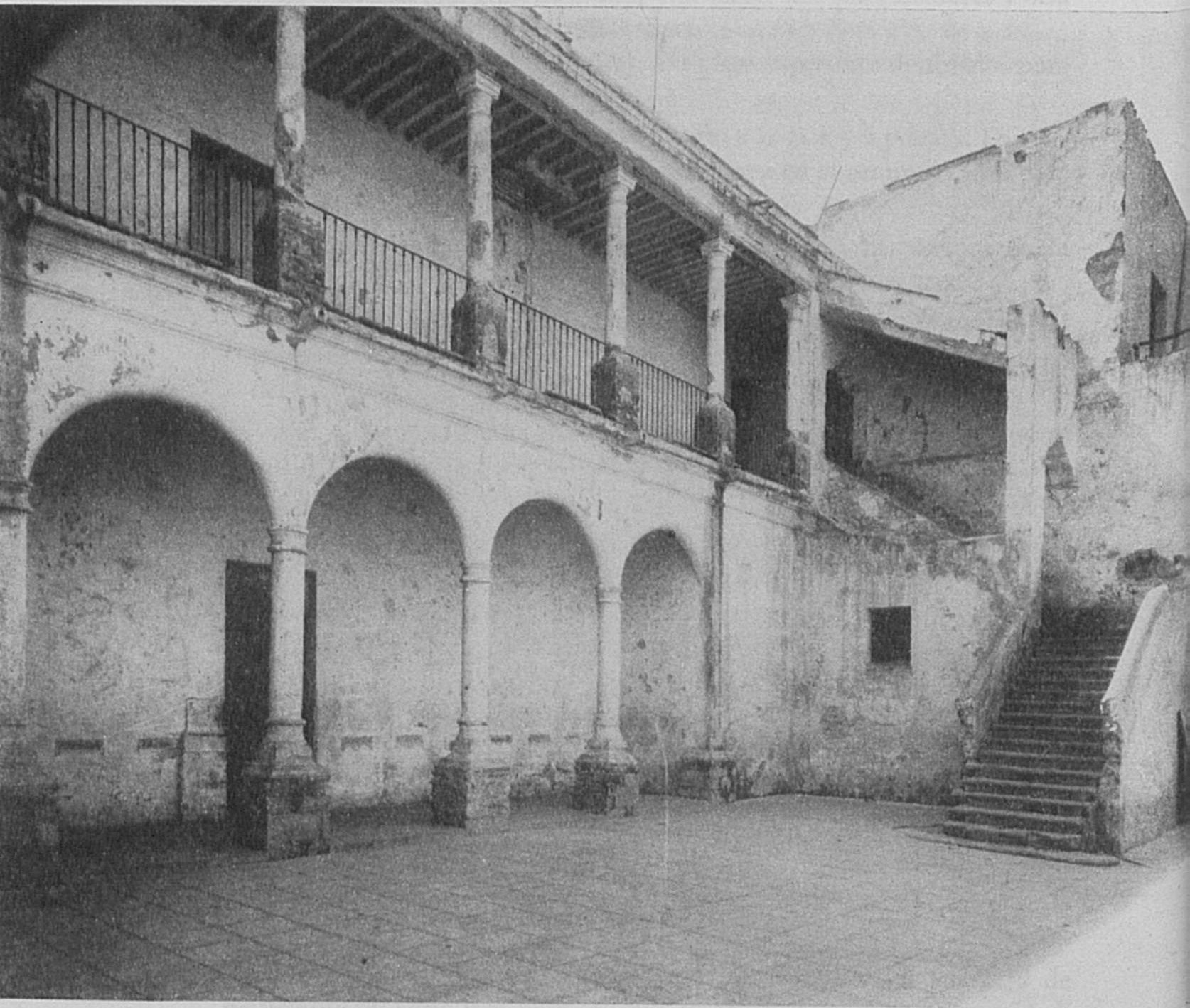

2. La parte de los arcos, antes de las obras de 1964 
DOI: http://dx.doi.org/10.22201/iie.18703062e.1968.37.858

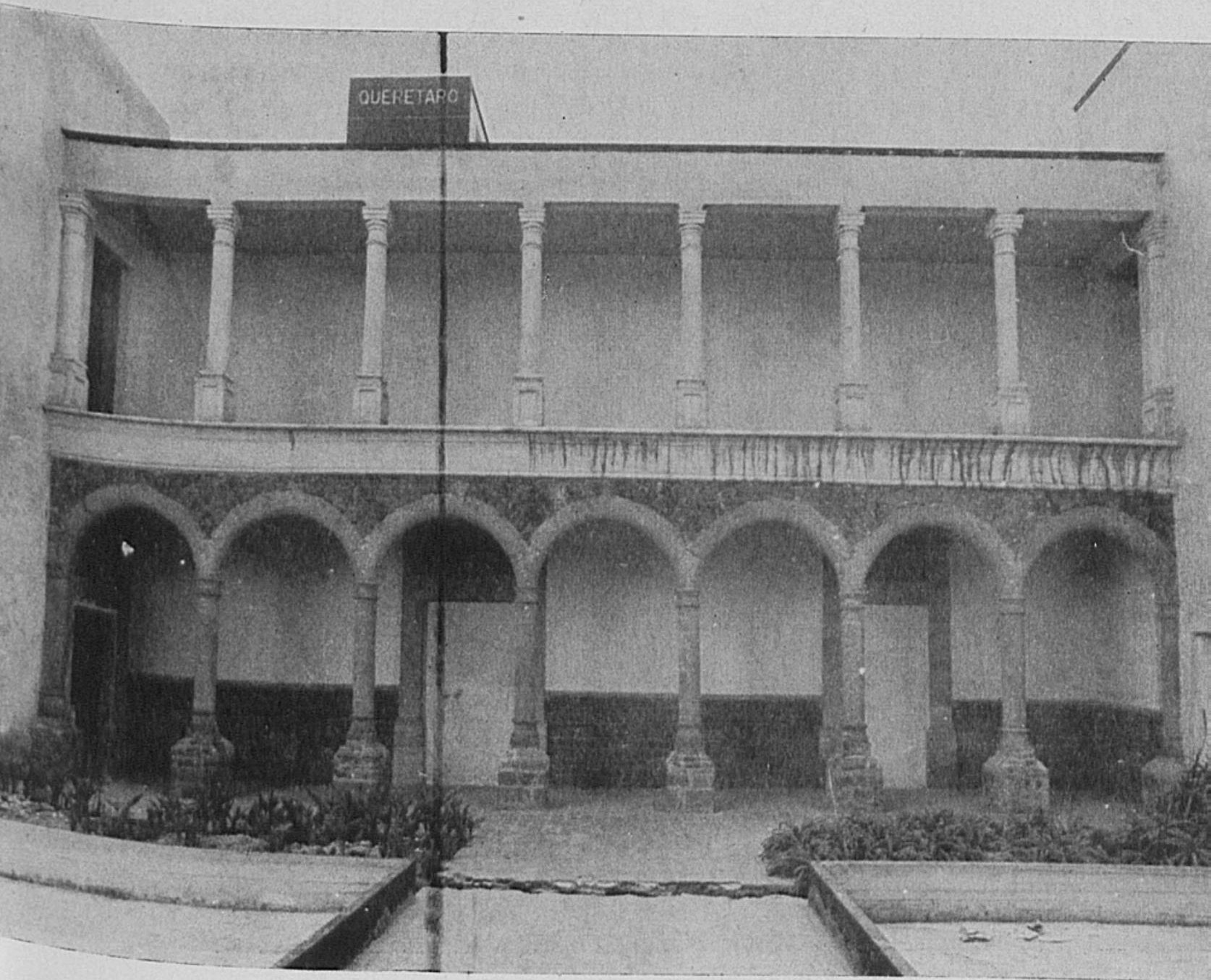

3. Los arcos, estado actual 

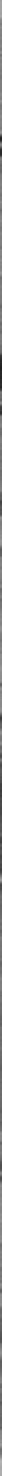

4. Fachada del Tecpan antes de su traslado 
DOI: http://dx.doi.org/10.22201/iie.18703062e.1968.37.858

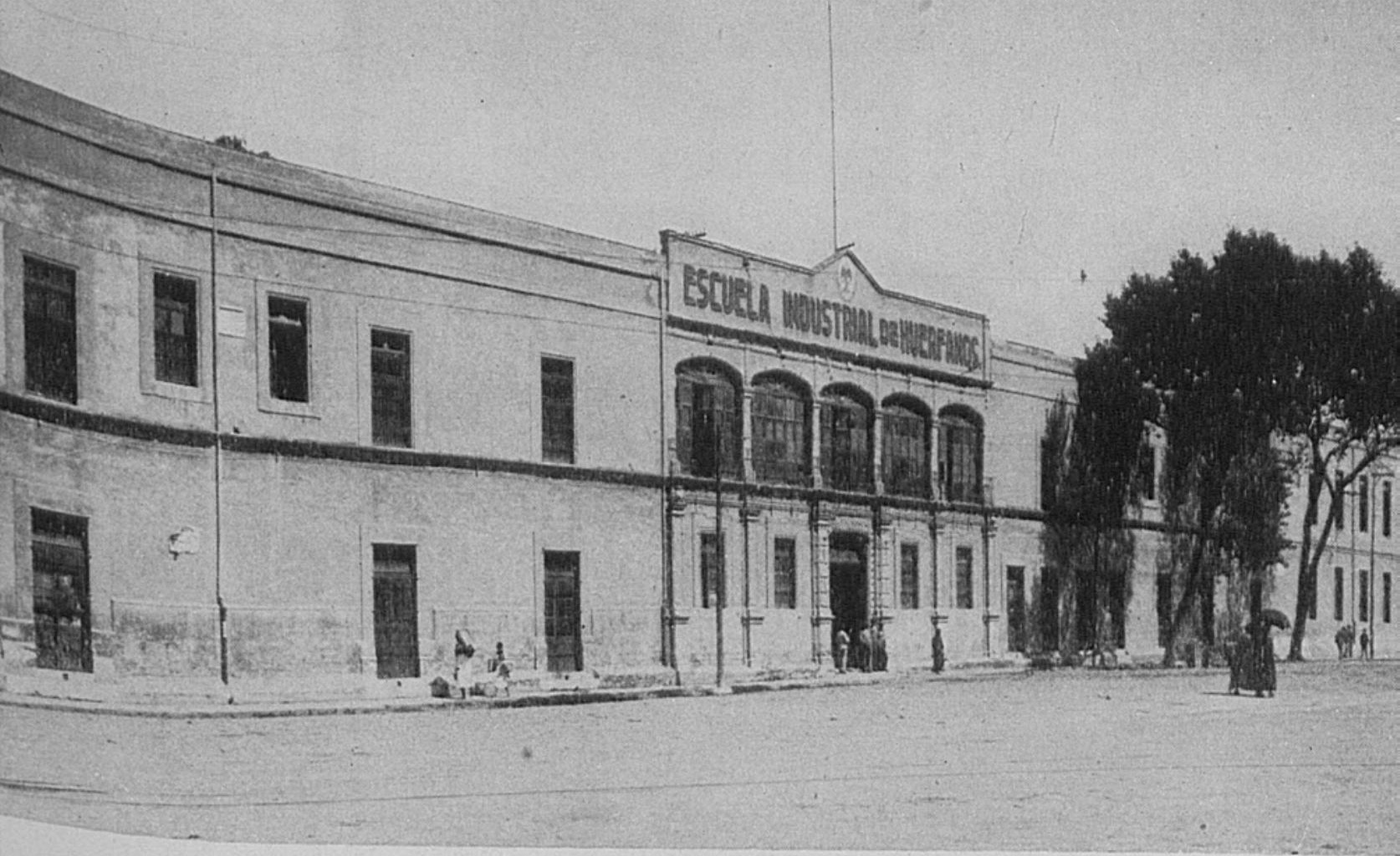

5. Fachada antes de las obras de 1964 
DOI: http://dx.doi.org/10.22201/iie.18703062e.1968.37.858

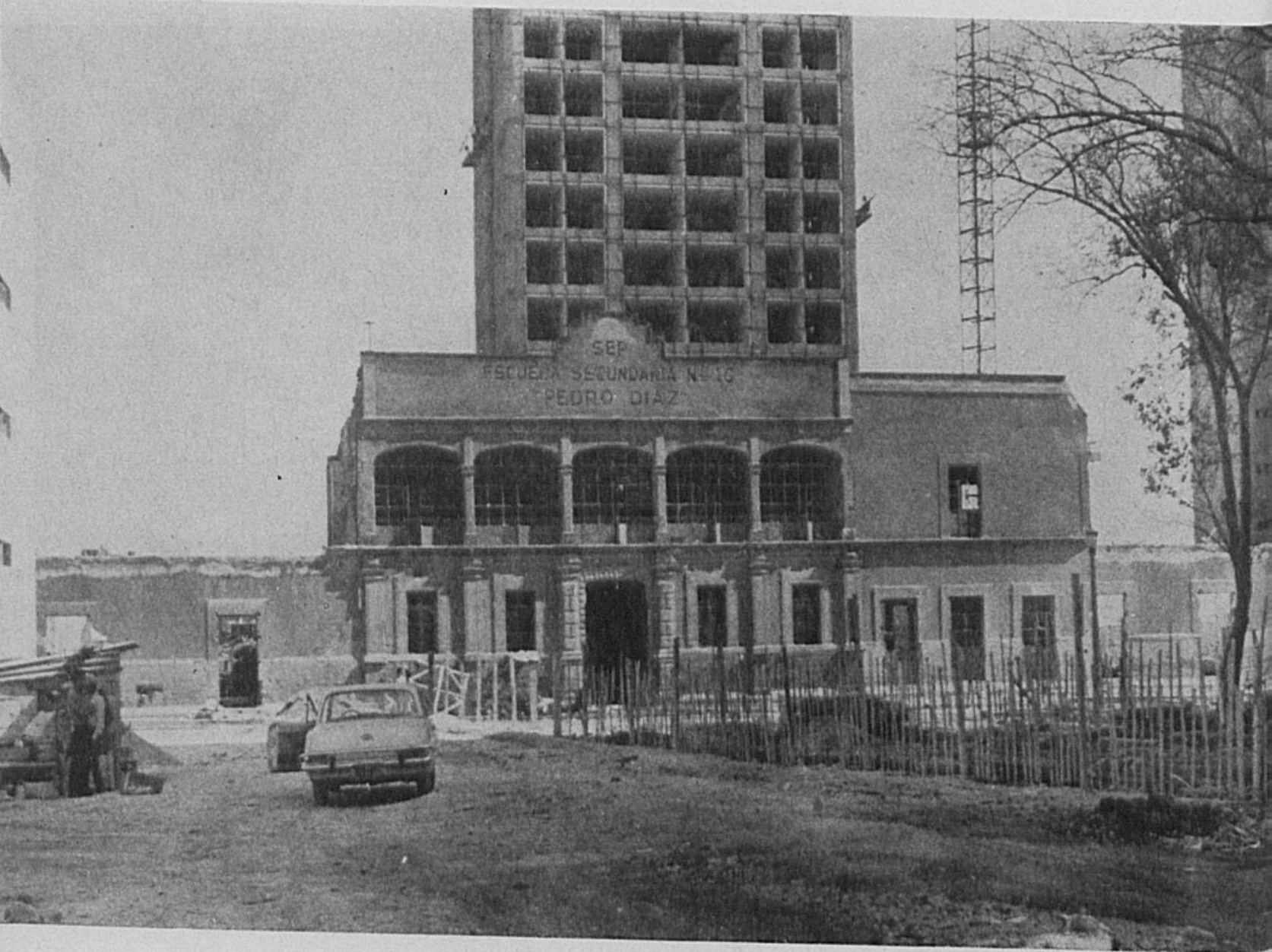

6. El Tecpan durante las obras de 1964 
DOI: http://dx.doi.org/10.22201/iie.18703062e.1968.37.858

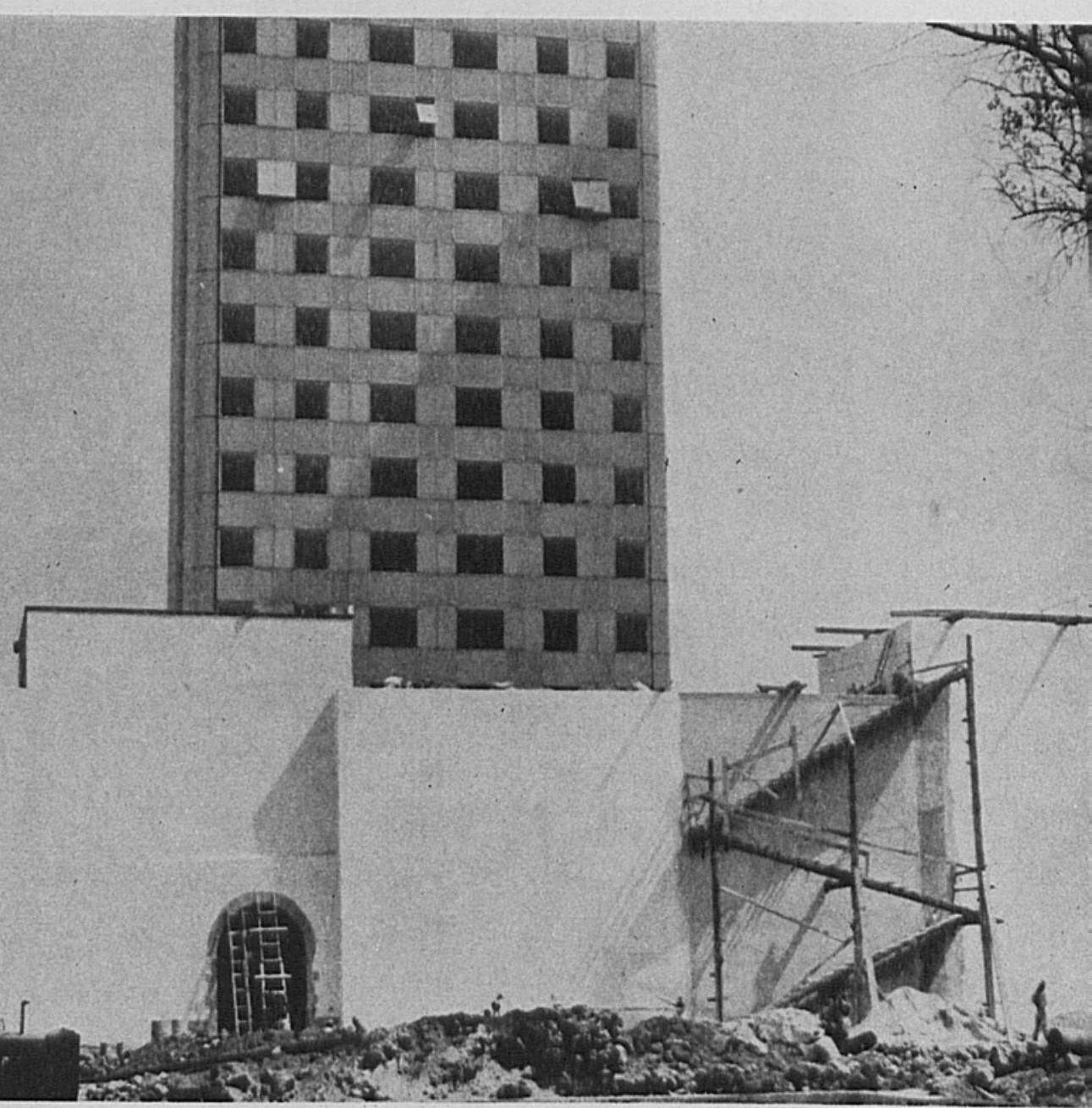

7. Estado del Tecpan, después del traslado de su fachada al Colegio de la Santa Cruz 
DOI: http://dx.doi.org/10.22201/iie.18703062e.1968:37:858

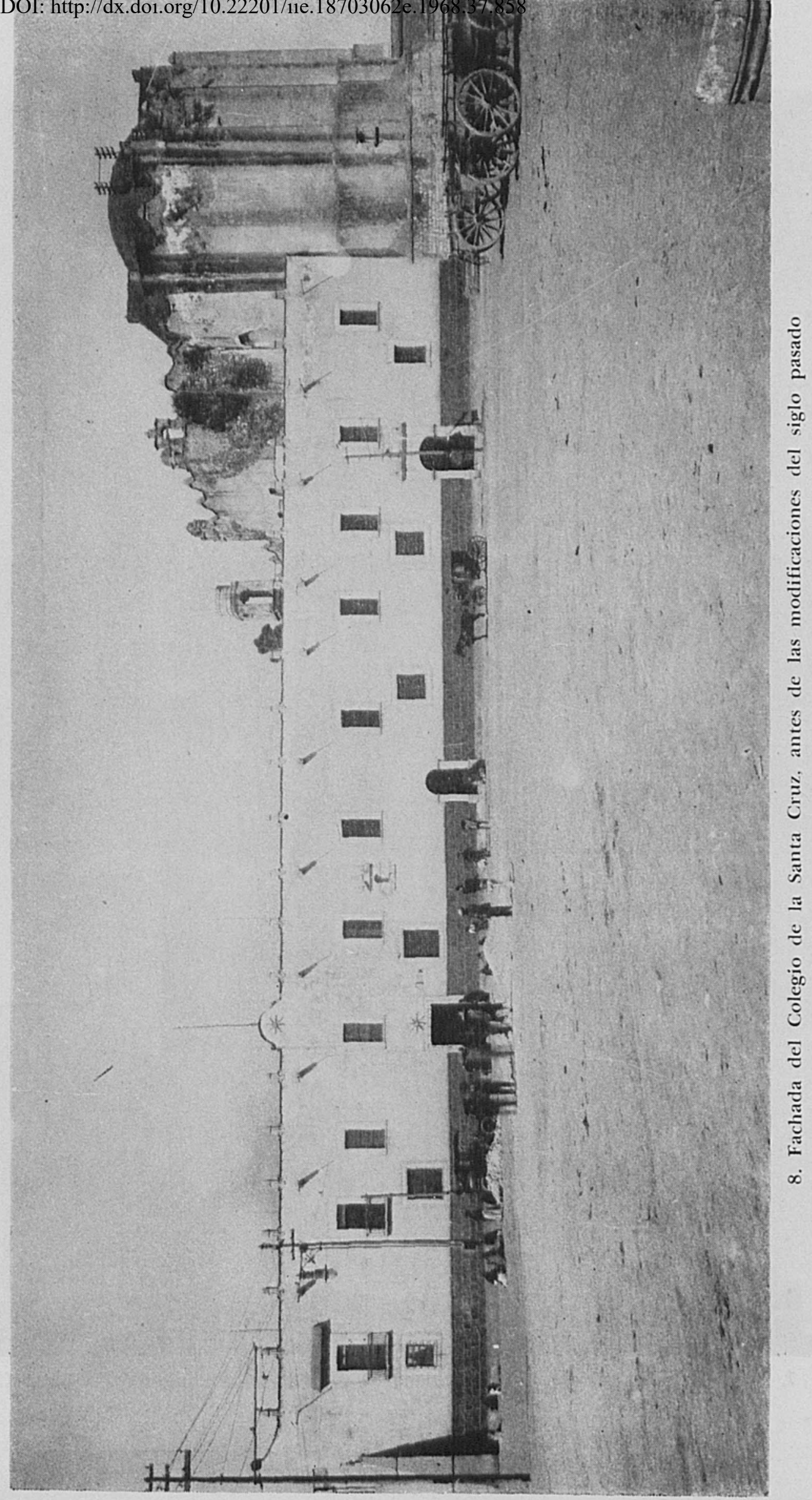


DOI: http://dx.doi.org/10.22201/iie.18703062e.1968.37.858

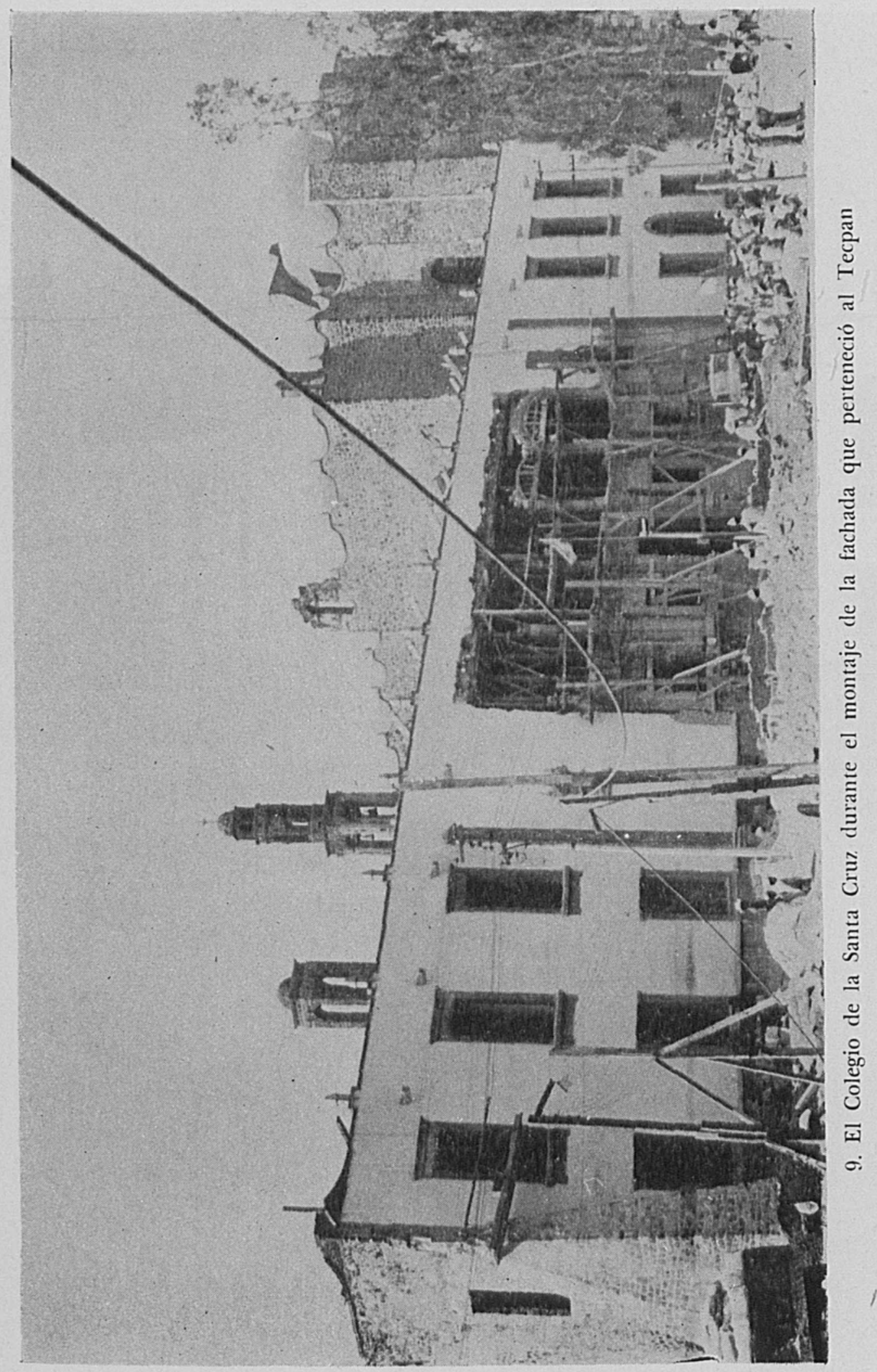




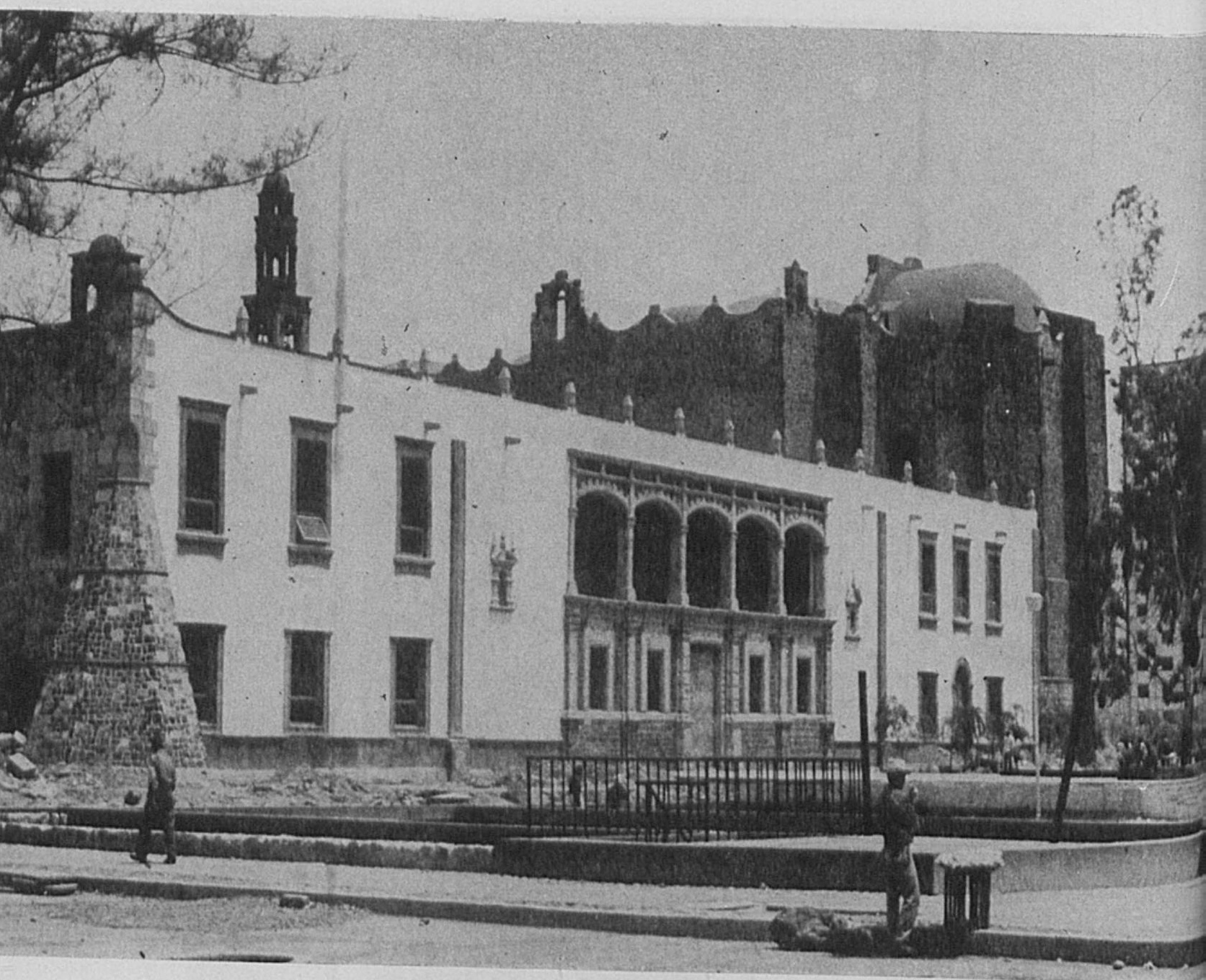

10. Colegio de la Santa Cruz. Estado actual 
DOI: http://dx.doi.org/10.22201/iie.18703062e.1968.37.858

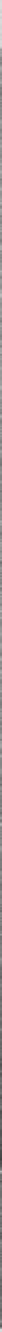

11. Portada dentro de un espejo de agua 


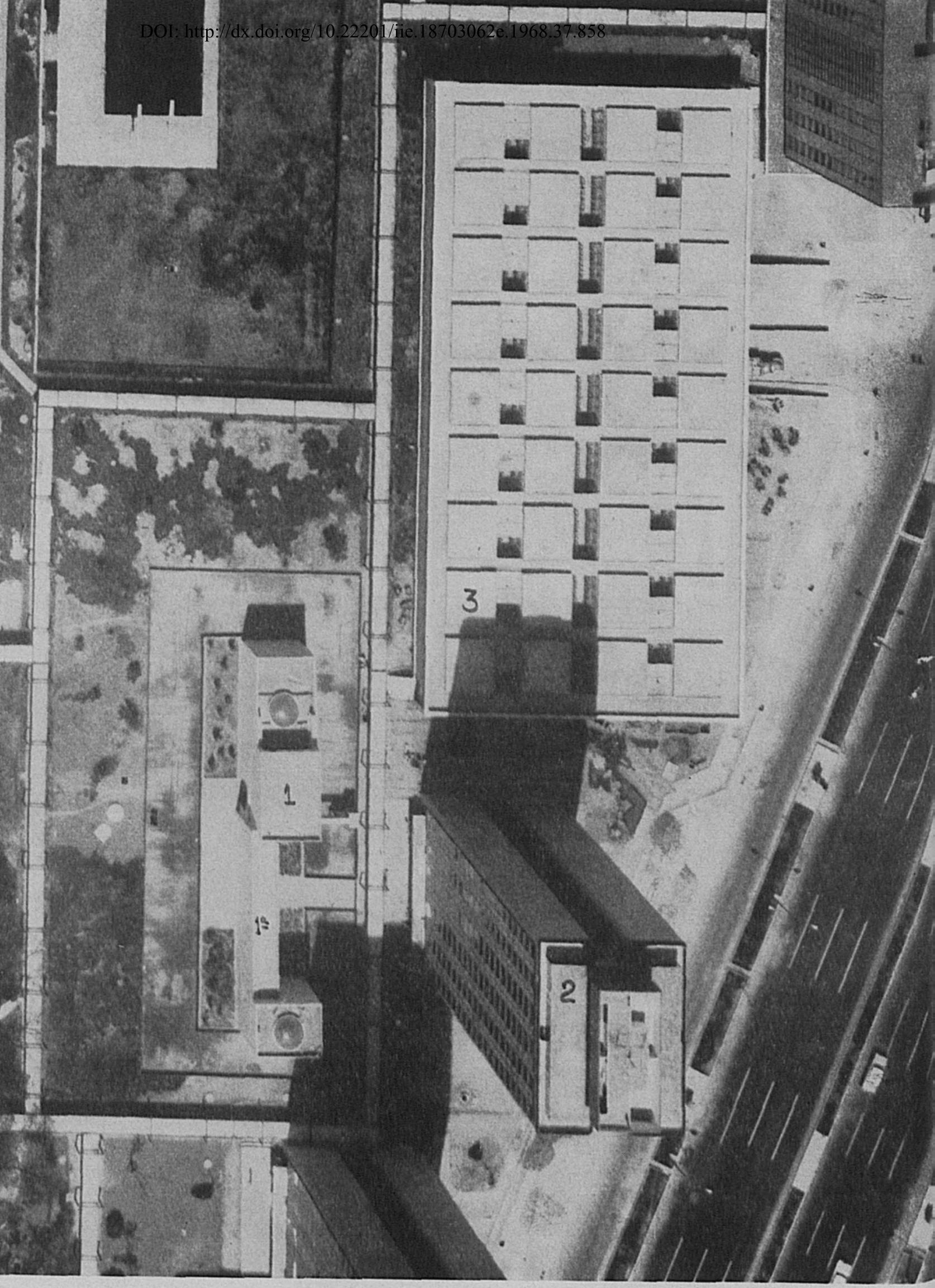

12. Relación de volúmenes del Tecpan y los edificios que lo rodean: 1. El Tecpan, 2. Torre de departamentos, 3. Estacionamiento 
de fundación el 11 de agosto de $1581 .^{3}$ Teniendo las obras un costo total de cuarenta mil doscientos pesos y cincuenta centavos. 4

El tecpan es uno de los más notables ejemplos de supervisión institucional ya que. se conservó coma dependencia oficial o civil desde el siglo xiv hasta nuestros dfas; con ocupantes tan distinguidos como el tlatoani Cuauhtémoc, último emperador mexica. Antes de las obras de 1964 el edificio mostraba una estratificación histórica que iba del siglo Xvi al siglo xix. Así su fachada estaba construida por un gran paño modificado el siglo xIX en cuyo centro se encontraba la fachada hecha en tiempo del virrey Bucareli, compuesta de "un primer cuerpo correspondiente a la planta baja con pilastras y contras dóricas entableradas, a los lados del entreje de la puerta otros dos entrejes con ventanas, cierran la composición y en el piso alto se repiten los mismos cinco tramos que corresponden a otros tantos, arcos, de tres centros, muy rebajados". " En su interior de la misma época, una portada barroca y puertas con sus clásicos marcos en cantera de jambas continuas; en 1939, según Justino Fernández podían "verse aun algunas antiguas mochetas y fracciones de muro de piedra formados con sillares pequeños, típicos de las construcciones del siglo xvi". La fachada posterior tenía dos pisos con columnas y arcos del siglo xvi en planta baja, y columnas con platabanda en planta alta, durante el siglo xvill se construye una escalera exterior limitada por dos arcos mixtilíneos con un tramo descubierto y otro cubierto, las demás dependencias modificadas para cumplir con su última función no tenían gran interés, conservándose sólo una crujía con arcos rebajados fabricados con ladrillos.

Dentro del proyecto del "Conjunto Urbano Nonoalco-Tlatelolco" el desaparecido Banco Nacional Hipotecario Urbano y de Obras Públicas consideró al centro histórico dentro de las obras, elaborando con este fin un programa especial. Por ello celebró una junta con la asistencia del doctor Eusebio Dávalos Hurtado, doctor Ignacio Bernal, arquitecto Mario Pani, arquitecto Pedro Ramírez Vázquez, arquitecto Jesús Aguirre Cárdenas, y el arquitecto Ricardo de Robina, autor del proyecto. En él se especifican los espejos de agua, iluminación, niveles arqueológicos de la zona, el piso de mármol de la Iglesia de Santiago y dentro del pro-

3 Justino Fernández. "Introducción al códice de Santiago Tlatelolco." Revista Mexicana de Estudios Históricos. México, 1939.

4 La cantidad asignada en el códice es de treinta y tres mil seiscientos pesos, pero esto evidentemente es un error al sumar las diferentes partidas consignadas.

5 Justino Fernández. "Introducción al códice de Santiago Tlatelolco." Revista Mexicana de Estudios Históricos. México, 1939. 
grama del Colegio de la Santa Cruz, su destino a Maseo de la Cultura Mexicana "respetando su distribución original". En este último se encuentra el siguiente punto relativo al tecpan "La fachada oriente, actualmente deformada con añadidos de la epoca porfiriana, serk enriquecida (sic) trasładando a ella la fachada del tecpan, perteneciente al siglo xvir".

El programa aprobado para el tecpan fue el siguiente: "En esta construcción se conservará la crujía poniente correspondiente al sigló xvI, dedicando la habitación del extremo norte a la exhibición de la pintura Cuauhtémoc del maestro Alfaro Siqueiros. La construcción estará rodeada por un espejo de agua y un acceso por el lado poniente.

La placa conmemorativa en mármol del siglo xvir será debidamente expuesta en una de las habitaciones. Dicho programa fue ejecutado en su totalidad no mediando ningún otro estudio al respecto, lo que trajo como consecuencia que al tratarse el monumento en forma aislada no se buscara siquiera una mínima área de protección, quedando una torre de departamentos a escasos cinco metros del tecpan, la que virtualmente lo aplasta.

Aunado a esto el haber cerrado con un espejo de agua su entrada lógica por el jardín, obliga al visitante a llegar a él, serpenteando entre las torres de departamentos produciendo una visión de conjunto desfavorable totalmente para el monumento. Su falta de importancia se acentúa al haber sido despojado de su fachada para trasladarla al Colegio de la Santa Cruz, que nunca tuvo ni pretendió tener una fáchada de la importancia de la del tecpan, ya que hemos visto la decadencia en que se encontraba el colegio en el siglo xvirr.

En todo esto no se siguió un criterio uniforme para los elementos del siglo xvir, ya que si la fachada se trasladó, en el tecpan se conservaron varias portadas interiores de la misma época, unas cegadas y otras en medio del espejo de agua. Al mostrarse carente de interés, ya que desde la plaza sólo se ve a través de un paso a cubierto, el tecpan no sólo es virtualmente desconocido sino que está en completo abandono. 